ÇOMÜ Uluslararası Sosyal Bilimler Dergisi 3(1), 125-134, 2018

COMU International Journal of Social Sciences 3(1), 125-134, 2018

\title{
Bağlanmanın Doğal Sonucu: Ayrılma Kaygısı
}

\author{
Isa Özgür ÖZER*
}

\begin{abstract}
Öz
Bu çalışmanın amacı, çocuklarda bağlanmaya ve DSM-5 tanı kriterlerine göre ayrılma kaygısı bozukluğuna ilişkin temel bilgileri ortaya koymaktır. Bu amaç doğrultusunda APA, Ebscohost, Springer gibi çeşitli veri tabanlarında "ayrılma kaygısı", "bağlanma", "çocuklarda kaygı bozuklukları" gibi anahtar sözcükler aratılarak, tam metin olarak ulaşılabilen kitap ve makaleler gözden geçirilmiştir. Yapılan bu incelemeler, ayrılma kaygısı ve bağlanma arasındaki yakın ilişkiyi ortaya koymuştur. Bu noktada ayrılma kaygısının iki farklı boyutta ele alınmasına gerek duyulmuştur. Bunlardan ilki bağlanmanın, özellikle de güvenli bağlanmanın bir işareti olarak ayrılma kaygısıdır. Bu kaygı tutarlı, mantkklı ve beklenen düzeyde bir kaygıdır. Diğer yandan ikinci boyut ise DSM-5'te tanımlanan, bir psikolojik bozukluk olarak ayrılma kaygısıdır.
\end{abstract}

Anahtar Kelimeler: Ayrılma kaygısı, bağlanma, çocuklarda kaygı bozuklukları.

\section{Natural Result of Attachment: Separation Anxiety}

\begin{abstract}
The aim of this study is to reveal basic information about attachment in children and separation anxiety according to DSM-5 diagnostic criteria. In accordance with this purpose, books and articles which are accessed as full text via searching keywords such as "separation anxiety", "attachment" and "anxiety disorders in children" in various databases such as APA, Ebscohost and Springer, were reviewed. These examinations have indicated close relationship between separation anxiety and attachment. At this point, it is necessary in this research to handle separation anxiety in two dimensions. The first of them is the separation anxiety as a sign of attachment, especially a secure attachment. This anxiety is consistent, rational and expected level. On the other hand, second one is separation anxiety that is stated as psychological disorder in DSM-5.
\end{abstract}

Keywords: Separation anxiety, attachment, anxiety disorders in children. 


\section{GíRiş}

Doğa, bugünkü koşullarla bile, çok az yeterlikle dünyaya gelmiş canlıların, tek başlarına hayatta kalmaları ve büyümeleri için yeterince elverişli değildir. Öyle ki çok daha karmaşık bir yapıda olan ve düşünme yetisiyle diğer tüm canlıların üzerinde tutulan insanoğlu da, doğduğu günden itibaren sığınacak bir limana, kendini koruyacak ve besleyecek bir nesneye veya kişiye intiyaç duyar. $\mathrm{O}$ halde bağlanma davranışının insanlarda hayati bir intiyaç olduğunu söylemek yanlış olmaz. Nitekim Bowlby de (1982) insanların bağlanmaya karşı doğuştan getirdikleri bir eğilim içinde olduklarını ve bağlanmak için yeterli biyolojik donanımla dünyaya geldiklerini dile getirmiştir.

Elbette bireylerin aralarında güçlü bir duygusal bağ kurdukları kişi veya nesnelerden -ki bu bebek ve çocuklarda bakım veren veya annedir- ayrı kalmak kaygı yaratacaktı. Şu durumda ayrılma, bağlanmadan ayrı düşünülemez. Bu nedenle esas amacı DSM-5'te kaygı bozuklukları grubu içinde yer verilen ayrılma kaygısı bozukluğunun genel özelliklerini ortaya koymak olan bu çalışmada, bağlanma kavramına, bağlanmanın doğal bir sonucu olan ayrılma kaygısına ve daha sonra ayrılma kaygısının patolojik görünümüne yer vermek gerekli görülmüştür.

\section{LITERATÜRDE BAĞLANMA VE AYRILMA KAYGISI}

Özellikle bağlanma davranışı, geçmişten bugüne birçok sosyal bilimcinin ilgi gösterdiği bir fenomendir. Bağlanma ve ayrılık kaygısını ilk kez dile getirenlerden biri olan Freud (1994), insanın ilk anksiyete deneyimini henüz doğum anında anneden ayrılma esnasında yaşadığını ve bebeklik yıllarındaki bağlanma davranışının altında yatan temel motivasyonun oral haz arayışı olduğunu iddia etmiştir. Buna göre bağlanma, oral arzuların karşılanması yani beslenmeyle yakından ilişkilidir. Buna karşın Harlow'un (1958) gerçekleştirdiği deneysel çalışmalar, beslenme ya da oral doyum sağlamanın, bağlanma için temel bir unsur olmadığını ortaya koymuştur. Bu deneylerde Harlow, yeni doğan maymunları annelerinden ayırarak laboratuvar ortamında alt ay boyunca vekil anneler tarafindan büyütülmelerini sağlamıştır. Bu vekil annelerden biri telden yapılmış, rahatSIz, ancak bir biberon yoluyla besleme özelliği olan, diğeri ise yavruları beslememesine karşın kumaştan yapılmış, yumuşak ve rahat bir ortam sağlayan yapay bir annedir. Maymunların vekil annelerle geçirdikleri zaman gözlemlendiğinde ortaya çıkan sonuç şaşırtıcı olmuştur. Bebek maymunlar tel anneyle açlık ihtiyaçlarını karşılayacak kadar vakit geçirirlerken, günlerinin büyük bir kısmını kumaştan yapıımış anneyle geçirmişlerdir. Ayrıca gerçekleştirilen korku testlerinde, korkutulan bebek maymunların kumaştan yapılan annelerine sığındığı kaydedilmiştir. Harlow'un tüm bu bulguları, bağlanma davranışında beslenmeden ziyade, bebek ya da çocuk için güvenli, rahat bir ortam sağlamanın önemli bir unsur olduğunu ortaya koymuştur. Benzer şekilde yaşamın ilk yılındaki temel güven ve güvensizlik duygularına dikkat çeken Erikson da (1977), bebeklerde temel güvenin yerleşmesi için sıcak ve koruyucu bir anne-çocuk ilişkisinin, bebeğin ihtiyaçlarını karşılamanın ve fiziksel olarak konforlu bir ortam sağlamanın önemine işaret etmiştir. Bu sayede bebek temel güven duygusu geliştirerek anneye bağlanır, dünyanın iyi bir yer olduğuna ilişkin bir inanç geliştirir.

En önemli bağlanma kuramcılarından biri olan Bowlby (1982), uzun süre goriller, şempanzeler gibi hayvan türlerini incelemiş, bağlanma kavramına evrimsel bakış açısıyla yaklaşmıştrr. Bu makalenin başında bahsedildiği üzere doğal seçilimin karşısında ayakta durabilmek 
için bağlanmak zorunda olan diğer canlılarda olduğu gibi, insanların da bağlanmak için gerekli fizyolojik ve biyolojik donanıma sahip olduklarını öne sürmüştür. Örneğin gülümsemek, ağlamak, dokunmak, emmek gibi refleksler bağlanma için en ilkel kabiliyetlerdir. Kendinden sonraki çoğu bağlanma kuramına da temel oluşturan Bowbly, bağlanmayı bir süreç olarak görmüştür. Doğumdan sonraki 8-12 haftalık süreci içine alan ilk aşamada bebekler henüz yabancı ayrımı yapamayacak durumdadır ve gülümseme ya da ağlama gibi tepkiler anne, baba ya da yabancı ayırt etmeksizin herkese karşı gösterilir. 2-3 aydan yedinci aya kadar süren ikinci evrede ise bebek annesini diğer insan figürlerinden ayırt etmeye başlayarak bağlanma tepkilerini anneye (bakım verene) yönlendirir. Bağlanma tepkilerinin annenin davranışlarından bağımsız olarak ortaya çıktığı üçüncü evre yedinci aydan 24. aya kadar olan süreyi kapsar. Bu aşamada bebekler artık bakım verenleriyle iletişim ve yakınlık kurma arayışı içerisindedir. Annenin varlığında huzur ve mutluluk, yokluğunda ise gerginlik ve rahatsızlık duyguları hakim olur (Kesebir, Kavzoğlu ve Üstündağ, 2011).

Bağlanmada bireysel farklılıklar olabileceğini düşünen Ainsworth ve arkadaşları (2014), yabancı durum testini geliştirmiş ve bu yolla çocukların bağlanma örüntüleri incelenebilmiştir. Gözleme dayalı olan bu değerlendirme yolu, çocuğu, annesiyle birlikte olduğu, annesinden ayrıldığı, annesiyle yeniden birleştiği ya da bir yabancıyla tek kaldığı bir dizi farklı durumun içerisinde bırakarak, bu durumlarda ne tür davranışlarda bulunduğunu kaydetmeyi içerir (Ainsworth ve Bell, 1970). Bu sayede Ainsworth, Bowlby'nin kuramını geliştirerek bağlanma stillerini güvenli (secure), kaygılı (anxious) ve kaçınan (avoidant) bağlanma olarak sınıflamıştır.

Bağlanma stillerine kısaca değinmeden önce ayrılma kaygısının bağlanmayla olan ilişkisini daha açık hale getirmekte yarar var. Ayrılma kaygısı her bağlanma stilinde ortaya çıkmasıyla genel olarak bağlanmanın doğal bir sonucudur. Ancak bu kaygının düzeyinin aşırı, normal ya da çok az olmasında bağlanma stillerinin rolü yadsınamaz bir gerçektir (Wright, Binney ve Smith, 1995; Dallaire ve Weinraub, 2006; Warren, Huston, Egeland ve Sroufe, 1997; Muris, Meesters, Melick ve Zwambag, 2001; Bar-Haim, Dan, Eshel ve Sagi-Schwartz, 2007; Muris ve Meesters, 2002). Örneğin Dallaire ve Weinraub (2005), bebeklik yıllarında, bakım verene kaygılı ve kaçınan stilde bağlanan çocukların, 6 yaşına geldiklerinde yaşadıkları ayrııma kaygısının, güvenli bağlanan çocukların yaşadıkları ayrılma kaygısının üzerinde olduğunu ortaya koymuştur. Başka bir araştırmada Warren, Huston, Egeland ve Sroufe (1997) de bebeklik ve çocukluk yıllarında kaygılı ve kaçınan bağlanma tarzına sahip olmanın, okul dönemi ve ergenlik yıllarında yaşanabilecek birtakım kaygı bozukluklarının - ayrılma kaygısını da içine alan - yordayıcısı olduğunu keşfetmiştir. Bar-Haim, Dan, Eshel ve Sagi-Schwartz (2007) ise güvenli bağlanma ve kaygılı bağlanmanın sonuçlarını incelediği bir araştırmada, bebeklik yıllarında kaygılı bağlanan çocuklarda, 11 yaşına geldiklerinde, güvenli bağlananlara göre daha sık okul fobisi geliştiğine tanıklık etmiştir. Bu sonucu gözden geçirirken, daha sonra da bahsedileceği üzere okul fobisinin ayrılma kaygısıyla ilişkisi unutulmamalıdır. Ayrııma kaygısı bozukluğu tanısı alan çocukların \%75'inde okul reddi de görülmektedir (Türkbay ve Söhmen, 2001). Benzer şekilde Muris ve Meester (2002) ile Muris, Meesters, Melick ve Zwambag'ın (2001) bulgularına göre de güvensiz olarak sınıflanan kaygılı ve kaçınan bağlanma tarzları, gelecekte yaşanması muhtemel kaygı bozukluklarıyla yakından ilişkilidir ve yine bu bozukluklardan birisi de ayrılma kaygısıdır.

Özetle ayrılma kaygısı, bağlanma ve onun farklı biçimleri tarafindan şekillendirilebilen bir fenomendir ve güvenli bağlanma da dahil olmak üzere hiçbir bağlanma tarzı, ayrıl- 
maya ilişkin kaygısızık durumu içermez. Ancak aralarındaki fark şu şekilde açıklanabilir: Güvenli bağlanan çocukların yaşadıkları ayrılma kaygısı düşük düzeyde ve mantıklı olması bakımından normal bir kaygıdır (Ainsworth, 1979; Ainsworth ve Bell, 1970; Ainsworth ve ark., 2014). Buna karşın yukarıda atffta bulunulan araştırmalardan hareketle güvensiz bağlanan çocukların yaşadıkları kaygının, hem daha yüksek hem de patolojik olmasalar dahi patolojik bir bozukluğa dönüşmeye aday olduğunu söylemek mümkündür.

\section{BAĞLANMA STILLERI}

\section{1. Güvenli Bağlanma}

Ainsworth’a (1979) göre güvenli bağlanmayı işaret eden en önemli belirti, çocuğun anneyi, çevreyi keşfederken güvenli bir üs olarak kullanmasıdır. Yani güvenli bağlanmış çocuklar annelerinin yanında çevreyle etkileşime girmekten kaçınmazlar. Bu sınıfta yer alan çocuklar yabancı durum testinde anneden ayrıldıklarında doğal olarak ayrılma kaygISı belirtileri gösterirler ve tek başlarına olduklarında yabancılardan kaçınırlar. Bu da zaten anne ve çocuk arasında kurulmuş güvene dayalı ilişkinin göstergesidir. Korunmaya muhtaç çocuk, güvenlik üssü ortadan kalktığında huzursuzluk içine girer ve anneyi arar. Anne odaya döndüğünde de onunla yakınlık kurma arayışı içinde olurlar ve yeniden rahatlamaları kolaydır. Güvenli bağlanan çocukların anneleri çoğunlukla, çocuklarının ihtiyaçlarına karşı daha duyarlıdır.

\section{2. Kaygılı Bağlanma}

Kaygılı bağlanan çocuklar annesi yanındayken bile çevreyi keşfetme konusunda isteksizdir ve çoğunlukla anneye yapışır. Bu grupta yer alan çocuklar yabancı durum testinde anneden ayrıldığında yoğun şekilde ayrılma kaygısı belirtileri gösterirler ve yabancılarla hiçbir şekilde iletişime geçmezler. Ayrılma esnasındaki yoğun kaygısına karşın anne döndügünde onunla temasa geçmez hatta iter ya da tam tersi anneye yapışıp kalır. Çocuklarının ihtiyaçlarına cevap verme düzeyinde tutarsızıklar olan ebeveynlerin çocuklarında böyle bir bağlanma tarzının görülmesi olasıdır.

\section{3. Kaçınan Bağlanma}

Kaçınan bağlanma örüntüsüne sahip çocuklar, yabancı durum testinin ayrılma aşamalarında annenin uzaklaşmasından neredeyse hiçbir şekilde etkilenmez, yeniden birleşme sırasında ise aktif temas kurmaktan kaçınırlar. Bu evrede anneyle ya da bağlanma figürüyle yakınlık kurmak yerine oyuncaklara ya da keşfedilmeyi bekleyen diğer ögelere dikkatlerini yöneltirler (Sümer, Sayıl ve Berüment, 2016).

Görüldüğü üzere, bağlanmada bireysel farkların olduğu ve her çocuğun yukarıda açıklanan bu bağlanma örüntülerinden birine uygun davranışlarda bulunacağı söylenebilir. Bu bireysel farkların oluşmasında ise belirleyici iki faktör rol oynamaktadır: Anne duyarılı̆̆ı ve çocuğun mizacı. Örneğin Main ve Solomon' a (1990) göre çocuğun ihtiyaçlarına verilen tepkilerin tutarlı ve dakik olması güvenli bağlanma; ihtiyaçlara ilişkin sürekli tepkisizlik ve çocuğa karşı mesafeli tutum kaçınan bağlanma; intiyaçların kimi zaman karşılanıp kimi zaman karşılanmaması ya da çocuğun özerkliğine zarar verecek müdahaleci bir anlayış ise kaygılı bağlanmayla ilişkilidir. Çocuğun mizacının etkisi ise şu şekilde kendini gösterebilir: Vaughn, Bost, ve van IJzendorn'a (2008) göre bakım verenleri ihtiyaçlarına duyarsız, biri çekingen olmak üzere iki farklı çocuk düşünülürse, çekingen olan çocuk 
kaygılı bağlanma geliştirirken diğeri anneye tamamen kayıtsız olmakla karakterize edilen kaçınan bağlanma davranışları sergileyebilir (Akt. Sümer, Sayıl ve Berüment, 2016). Bu da büyük ölçüde mizacın yarattlğı sonuçtur.

Buraya kadar olan kısım, makalenin başlığında belirtilen, ayrılma kaygısını bağlanma ve onun farklı biçimlerinin bir sonucu olarak gören düşünceyi okuyuculara aktarabilmeyi amaçlamıştr. Bir şeye bağlı ya da sahip olmadan, onu kaybetmekten korkmak mümkün değildir. Elde tutulan değerli bir şey (Örneğin bir anne), aynı zamanda kaybetmekten korkulan şeydir. Yukarıda en ideal bağlanma tipi olarak ele alınan güvenli bağlanmanın özelliklerine bakıldığında, çocuk için normal olan davranışın, annesinden ayrıldığı veya yabancılarla baş başa kaldığında kaygılanmak olduğu belirtilmiştir. Aksi bir durumun yaşanması, yani bir çocuğun bakım vereninden ayrılsa da hiçbir olumsuz tepki göstermemesi ya da aşırı olumsuz, mantıksız ya da tutarsız tepkiler göstermesi sağlıksız bir bağlanma stilini işaret etmektedir. Bu açıdan güvenli bağlanan çocukların gösterdiği gibi tutarlı, rasyonel ve aşırıya kaçmayan ayrılma kaygısı, patolojik değil, normal ve beklenen bir kaygıdır. Öyle ki ayrıma kaygısı, çocuğun duygusal ve bilişsel gelişiminin sağıklı olduğuna ilişkin bir göstergedir (Hock, Eberly, Bartle-Haring, Ellwanger ve Widaman, 2001). Kaygının normal olup olmadığının nasıl sorgulanacağı ise aşağıda açıklanmıştır.

\section{BIR RUHSAL BOZUKLUK OLARAK AYRILMA KAYGISI}

Bağlanmanın doğal sonucu olmasına karşın ayrılma kaygısı, çocuğun gelişimsel düzeyine göre normal olan ayrılma kaygısının dışında kalan, yoğun bir kaygı içinde olmakla seyrettiği durumlarda bir bozukluk olarak da ele alınmaktadır.

\section{1. Tanı Kriteri}

Amerikan Psikiyatri Derneği (2013), Ayrılma kaygısını patolojik olarak görmek için ön koşul olan tanı ölçütlerine DSM-5'te şu şekilde yer vermiş̧ir:

A) Aşağıdaki belirtilerin en az üçünün görülmesiyle anlaşılan, bireyin bağlandığı kişiden ayrılmaya ilişkin gelişimsel olarak uygunsuz ve aşırı korku ya da endişe duymasıdır:

1) Evden ya da bağlandığı başlıca kişilerden ayrıldığında ya da ayrılmayı beklediğinde aşırı sıkınt duyma.

2) Bağlanılan başlıca kişileri kaybetme ya da doğal afet, hastalık, yaralanma gibi onların başına gelebilecek muhtemel kötülüklere ilişkin sürekli ve aşırı endişe.

3) Bağlanma figüründen ayrılmaya neden olacak olumsuz bir olay yaşamaya ilişkin sürekli ve aşırı endişe.

4) Ayrılma korkusundan dolayı evden okula ya da başka herhangi bir yere gitmeyi sürekli reddetme.

5) Bağlandığı başlıca kişiler olmadan evde ya da diğer ortamlarda kalmaya karşı sürekli bir korku ya da endişe duyma.

6) Bağlandığı başlıca kişiler yanında olmadan ya da evden uzakta olduğunda uyumayı sürekli reddetme.

7) Ayrılık teması içeren ve tekrarlayan kabuslar görme

8) Başlıca bağlanma figüründen ayrıldığında ya da ayrılmayı beklediğinde tekrarlayan 
fiziksel şikayetler.

B) Korku, kaygı ya da kaçınma davranışları süreklidir. Çocuklarda en az 4 hafta gözlenmelidir.

C) Bozukluk, sosyal, mesleki, akademik ya da diğer önemli alanlarda dikkate değer sıkıntı ve bozulmaya neden olur.

D) Bozukluk, hipokondriyazis bozukluk, genel anksiyete bozukluğu, agorafobi, psikotik bozukluklar veya otizm spektrum bozukluk gibi başka bir bozuklukla daha iyi açıklanamaz (s. 190).

Tanı ölçütlerinin dışında, ayrılma kaygısı tanısını destekleyen birtakım genel özellikler de bulunmaktadır. Türkbay ve Söhmen (2001), ayrılma kaygısı tanısı almış olan çocukların \%75'inde okul reddinin görüldüğünü ortaya koymuştur. Aynı çalışmada ayrıca, ayrılma kaygısı bozukluğu olan çocukların, diğerlerine göre daha içe dönük oldukları tespit edilmiştir. Bunların dışında, ayrılma kaygısı bozukluğu olan çocuklar hırsızlar, adam kaçıranlar, hayvanlar, canavarlar, karanlık gibi kendilerince tehlike olarak algıladıkları nesne ve durumlardan korkabilirler. Kendilerini bağlanma figürlerinden ayırmaya zorlayan birine öfke ve saldırganlık gösterebilirler. Özellikle karanlıkta veya yalnızken, odasına bakan insanlar görme, yaratıklar görme gibi sıradışı algısal deneyimler geçirebilirler (American Psychiatric Association, [APA], 2013).

\section{2. Yaygınlık}

Ayrılma kaygısı bozukluğu, çocuklardan oluşan klinik örneklere göre, her yüz çocuğun dördünde ortaya çıkmaktadır (Massi, Mucci ve Millepiedi, 2001). Cinsiyet bakımından bozukluğun görülme sıklığında ya da gözlenen semptomlarda bir farklılık olmamasına karşın, Yaşın artmasıyla birlikte bozukluğun görülme sıklığının azaldığı ve farklı gelişimsel düzeydeki çocuklarda farklı semptomların ağırlıklı olarak görüldüğü bilinmektedir (Francis, Last ve Strasuss, 1987). Buna göre, 5-8 yaş arasındaki çocuklarda en sık görülen belirti, bağlanma figürlerinin başına kötü bir şey geleceğinden yoğun bir şekilde endişe duymaktır (\%85). Aynı zamanda bu yaş grubunda ayrılma teması içeren kabuslar görme sıklığı geç çocukluk dönemindeki çocuklardan fazladır. 9-12 yaş arasındaki çocuklarda ayrılma üzerine aşırı bir sıkınt duyma en yaygın belirtidir (\%79) ve ergenlerle karşılaştrıldığında bu yaş dönemindeki çocuklarda bu belirtinin ergenlere göre daha fazla görüldüğü bulunmuştur. 13-16 yaş arasındaki ergenlerin de tamamının okul günlerinde fiziksel şikayetlerde bulunarak (hasta numarası yapmak) okuldan kaçmaya çalıştı̆ı görülmüştür. Yaşları 5 ile 12 arasında değişen çocuklarla yapılan bir araştırmada ise ayrılma kaygısı bozukluğu olan çocuklarda en sık görülen belirtilerin sırasıyla; okula gitmeyi reddetme, evden her ayrıldığında aşırı kaygılanma ve ayrılma durumunda fiziksel şikayetlerde bulunma olduğu görülmüştür (Bahalı, Tahiroğlu, Avcı, 2009). Irmak ve arkadaşları (2016) da ayrılma kaygısı bozukluğu olan bir ergenin en sık görülen davranışının okula gitmemek/istememek olduğunu kaydetmiştir.

Ayrılma kaygısı bozukluğunun Türkiye'deki genel durumuna bakıldığında, okul öncesi öğretmenlerinin en sık karşılaşthğı üç davranış bozukluğundan biri olduğu söylenebilir (ikiz, Otlu ve Vural, 2016). Başka bir bulgu, çocuk kliniklerine türlü şikayetlerle başvuran çocukların \%14'ünün ayrılma kaygısı bozukluğu tanısı almasıdır ve bu oranla çocuklarda en sık karşılaşılan üçüncü bozukluk olduğu görülmüştür (Göker, Güney, Dinç, Hekim ve Üneri, 2015). 


\section{3. Risk Faktörleri ve Prognoz}

Ayrılma kaygısı bozukluğunun bilinen nörolojik veya biyolojik bir nedeni bulunamamıştır (American Psychiatric Association, [APA], 2013). Bunlardan ziyade bu bozukluğun çevresel şartlardan etkilendiği söylenebilir. DSM-5'te, ayrılma kaygısının çoğunlukla bir yaşam stresinin ardından geliştiği belirtilmiştir. Bu stresli yaşam olaylarına okul değişimi, ebeveynlerin boşanması, yeni bir eve taşınma, göç etme ya da başlıca bağlanma figürlerinden birinin uzun süreli bir hastalık geçirmesi örnek olarak verilebilir. Yani sebepleri çoğunlukla çevreseldir.

Risk teşkil eden bir diğer faktör, ailede psikiyatrik bir bozukluk öyküsünün olmasıdır. Türkbay ve Söhmen (2001) de ayrılma kaygısı tanısı almış olan çocukların \%45'inin ailesinde daha önce benzer problemler yaşandığını ortaya koymuştur. Aynı araştırmada Ayrılma kaygısı bozukluğu olan çocukların ailelerinin, Eysenck kişilik envanterinin (Eysenck, Eysenck ve Barret, 1985) psikotiklik ve nevrotiklik boyutlarında, diğer annelere göre çok daha yüksek puan aldıkları tespit edilmiştir. Yine aileye ilişkin bir diğer çevresel risk faktörü ise ebeveynlerin birbirleriyle ve çocuklarıyla kurdukları ilişkinin niteliğidir. Daha önce bahsedildiği üzere Ainsworth (1979), güvenli bağlanan bebeklerin, anneleri tarafindan daha duyarlı bir bakım gördükleri, korundukları ve intiyaçlarını anneleri yoluyla karşılayabildiklerini dile getirmiştir. $O$ halde ebeveynlerinin her daim yanında olacaklarını hissedemeyen, her an annenin sevgisini kaybetmekle tehdit edilen, ihtiyaçlarına tutarsız bir biçimde hassasiyet gösterilen çocuklarda ayrılma kaygısının gelişmesi beklenen bir durum olacaktır. Bunun yanında ailede karı-koca tartışmaların sık yaşanması, boşanmanın sık sık dile getirilmesi gibi etkenler de çocukta ayrılık düşüncesini tetikleyecek ve buna ilişkin yoğun bir kaygı yaşamasına sebep olabilecektir (Filiz Gültekin, kişisel görüşme, 3 Nisan 2017)

\section{4. Tedavi}

Ayrılma kaygısı bozukluğunun giderilmesinde, farmokolojik tedavinin yanı sıra psikoterapötik ve psiko eğitsel tedavi/müdahaleler de önemli bir işleve sahiptir. Çocuğun yaşadığı yoğun kaygının üstesinden gelmesi, depresyondan korunması ve bozukluğun diğer etkilerini gidermek adına antidepresanlar, serotonin takviyesi ve benzodiazepinler yaygın olarak kullanılmaktadır (Masi, Mucci ve Millepiedi, 2001).

Psikoterapötik müdahalelere gelindiğinde Davranışçı ve Bilişsel-Davranışçı Terapilerin, ayrılma kaygısı bozukluğunun üstesinden gelmede önemli bir yeri olduğunu söylemek mümkündür. Sistematik duyarsızlaştırma, model olma, işlevsel davranış değerlendirmesi ve yüzleştirme gibi davranış̧̧ı müdahaleler tedavide kullanılan başlıca tekniklerdendir. Çocuğun bilişsel süreçleriyle de çalışan, bilişsel yeniden yapılandırma, mantık dışı inançları tartş̧ma, otomatik düşünceleri belirleme ve değişme gibi bilişsel-davranış̧ı temelli uygulamalara da başvurulabilir (Doobey, 2008, Phelps, Cox ve Bajorek, 1992). Bunların dışında yine davranışçı terapinin içinde yer alan EMDR (Göz Hareketleri Duyarsızlaştırma ve Yeniden İşleme Yöntemi), tedavi yöntemi olarak kullanılabilmektedir. Morissey (2013), aile terapisiyle birlikte 14 EMDR oturumundan oluşan tedavi yönteminin ayrılma kaygısıyla başa çıkmadaki etkililiğini ortaya koymuştur.

Daha önce bahsedildiği üzere ayrılma kaygısı bozukluğu olan çocukların \%75'inde okul reddinin de olduğu düşünüldüğünde, psiko-eğitsel müdahalelerin ve okul-aile iş birliği- 
nin önemini dile getirmek kaçınılmazdır. Masi, Mucci ve Millepiedi (2001) ebeveyn ve çocuğun eğitimini, okul personeli-uzman-aile iş birliğini kurmayı ve çocuğun özerkliğini ve yeterliğini arttırmaya yönelik çocukla doğrudan çalışmayı başlıca müdahaleler olarak belirlemiştir. Bu müdahalelerin iyileştirici yanı dışında, önleyici bir işlevinin de olduğu gözden kaçırılmamalıdır. Etkililiğini ölçmek üzere bir araştırmaya rastlanmamış olsa da Türkiye'de, okula yeni başlayan birinci sınıfların eğitimine, diğer kademelerden bir hafta önce başlayarak bu süreyi birinci sınıfların uyum sağlaması adına kullanmak, önleyici amaçla yürürlüğe konulan bir uygulama örneğidir. Elbette ayrılma kaygısı bozukluğu çoğunlukla okul öncesi dönemde ortaya çıksa da, nadiren de olsa okul çağında ortaya çıkabilmektedir (APA, 2013). Bu açıdan henüz böyle bir bozukluğun ortaya çıkmadığı çocuklarda okula alıştırma, daha sonra karşılaşılabilecek bir ayrılma kaygısının ya da yakın arkadaşı olan okul fobisinin önüne geçebilir.

\section{SONUÇ VE ÖNERILER}

Sonuç olarak ayrılma kaygısı, bu çalışmada ele alındığı üzere hem doğal bir tepki hem de bir çeşit nevrozdur. Bir çocuk söz konusu olduğunda bunun doğal mı yoksa nevrotik mi olduğunun ayrımını yapmak ise ebeveynler için epey güçtür. Örneğin Türk aile yapısı göz önünde bulundurulduğunda, annesi olmadan uyumayan bir çocuk hiç kimseyi rahatsız etmeyebilir. Aksine aile bağlarına epey önem verilen böylesi bir toplumda, çocuğunun kendisi olmadan bir yere gitmemesi, bir anne veya baba için övünç kaynağı dahi olabilir.

Ayrılma kaygısının bilinen nedenlerini çevresel faktörler oluşturmaktadır. Çocuğun ilk ve en önemli çevresinin ailesi olduğu düşünülürse ebeveynlerin, bozukluğun ortaya çıkmasını önlemede önemli bir rol üstlendiğini söylemek yanlış olmaz. Her şeyden önce anne baba olarak çocuğun ihtiyaçlarına yeterli düzeyde cevap vermek, sıcak, güven verici ve huzurlu bir aile ortamı oluşturmak bir gerekliliktir. Bu sayede çocuğun, aile bireylerinin hayat boyunca yanında olacakları ve onu koruyacaklarına kuvvetle inanması sağlanabilir. Elbette anne ve babaların koruyucu ve güven verici tutumunun altında, çocuğa ailenin güvenli, ancak ailenin olmadığı her yerin güvensiz olduğu mesajı yatmamalıdır. Bu açıdan aile, çocuğun özerkliğini destekleyen, bağımsız davranışlarını ödüllendirebilen bir anlayışa sahip olmalıdır. Ayrılma kaygısı bozukluğunu stresli yaşam olaylarının da tetiklediği daha önce söylenmişti. Bir çocuk için bazen yeni bir eve taşınmak, okul değiştirmek hiç de kolay olmayabilir. Bu noktada aile, bu tür değişimlere girişmeden önce, çocuklarının da fikrini alıp tartışarak demokratik bir ortam yaratırsa, bu tür yaşam olaylarının verebileceği stres azaltılabilir.

Ayrılma kaygısı bozukluğu, içinde bulunduğu kültür bağlamında değerlendirilmesi gereken bir bozukluktur. Bağlanmayla olan ilişkisi, içinde bulunulan kültürdeki bağlanma alışkanlıklarına veya aile geleneklerine hakim olunmasını gerekli kılmaktadır. Çocuklarda en sık rastlanan bozukluklardan biri olmasına karşın Türkiye'deki alan yazında yeteri kadar ilgi görmediği söylenebilir. Bu makalede bağlanmayla ayrılma kaygısı arasında kurulan ilişki bu alan yazının okunarak yorumlanmasına dayandırıımıştır. Burada yer alan çıkarımları destekleyecek, betimsel ya da deneysel araştırmaların yapılması önerilebilir. Ayrılma kaygısını patolojik ve normal olarak daha keskin çizgilerle ayırabilmek adına karşılaştırmalar içeren araştırmalar da tanı ve çocuğa yaklaşımda önem taşıyacaktır. Son olarak bu makale, bağlanma ve ayrıma kaygısına genel bir bakış sağlaması ve psikolojik bozukluklar için başvurulabilecek en güncel kaynağı (DSM-5) içermesi yönüyle faydalı bulunmaktadır. 


\section{KAYNAKÇA}

Ainswonh, M. D. S. (1979). Infant-mother attachment. American Psychologist, 34 (10), 932-937.

Ainsworth, M. D. S., ve Bell, S. M. (1970). Attachment, exploration, and separation: Illustrated by the behavior of one-year-olds in a strange situation. Child Development, 41 (1), 49-67.

Ainsworth, M. D. S., Blehar, M. C., Waters, E. ve Wall, S. (2014). Patterns of Attachment: A psychological study of the strange situation. NY: Psychology Press.

American Psychiatric Association. (2013). Diagnostic and statistical manual of mental disorders (5th edition.). Washington: Amerikan Psychiatric Publishing.

Bahalı, K., Tahiroğlu, A. Y., Avcı, A. (2009). Okul reddi olan çocuk ve ergenlerin klinik özellikleri. Anadolu Psikiyatri Dergisi, 10 (1), 310-317.

Bar-Haim, Y., Dan, O., Eshel, Y. ve Sagi-Schwartz, A. (2007). Predicting children's anxiety from early attachment relationships. Journal of Anxiety Disorders, 21 (1), 1061-1068.

Bolwby, J. (1982). Attachment and loss: Attachment (2nd edition.). NY: Basic Books.

Dallaire, D. H. ve Weinraub, M. (2005). Predicting children's separation anxiety at age 6: The countributions of infant-mother attachment security, maternal sensitivity, and maternal separation anxiety. Attachment \& Human Development, 7 (4), 393-408.

Doobay, A. F. (2008). School refusal behavior associated with separation anxiety disorder: A cognitivebehavioral approach to treatment. Psychology in the Schools, 45 (4), 261-272.

Erikson, E. (1977). Childhood and society (Revised ed.). London: Paladin Grafton Books.

Eysenck, S. B. G., Eysenck, H. J. ve Barret, P. (1985). A revised version of the psychoticism scale. Personality and Individual Differences 6 (1), 21-29.

Francis, G., Last, C. G. ve Strauss, C. C. (1987). Expression of separation anxiety disorder: The roles of age and gender. Child Psychiatry and Human Development, 18 (2), 82-89.

Freud, S. (1994). Psikanaliz üzerine (7. Baskı). (A. A. Öneş, Çev.). İstanbul: Say Yayınları. (Orijinal çalışma basım tarihi 1910.)

Göker, Z., Güney, E., Dinç, G., Hekim, Ö., Üneri, Ö. ş. (2015). Çocuk ve ergenlerde anksiyete ile ilişkili bozuklukların klinik ve demografik özellikleri: Bir yıllık kesitsel bir örneklem. Klinik Psikiyatri, 18 (1), 7-14.

Harlow, H. F. (1958). The nature of love. American Psychologist, 13 (12), 673-685.

Hock, E., Eberly, M., Bartle-Haring, S., Ellwanger, P., Widaman, K. F. (2001). Separation anxiety in Parents of Adolescents: Theoretical Significance and Scale Development. Child Development, 72 (1), 284-298.

Irmak, M. Y., Irmak, A., Murat, D., Demir, N. Ü. (2016). Ayrılık anksiyetesi bozukluğu ile ilişkili okul reddi; bir ergen olgu sunumu. Journal of Contemporary Medicine, 6 (4), 357-360.

İkiz, F. E., Otlu, B. M., Vural, D. E. (2016). Erken çocukluk döneminde görülen problem davranışlar: Öğretmenlerin değerlendirmesi. Mehmet Akif Ersoy Üniversitesi Sosyal Bilimler Enstitüsü Dergisi, 8 (17), 216-229.

Kesebir, S., Kavzoğlu, S. ve Üstündağ, M. F. (2011). Bağlanma ve psikopatoloji. Psikiyatride Güncel Yaklaşımlar, 3 (2), 321-342.

Masi, G., Mucci, M. ve Millepiedi, S. (2001). Separation anxiety disorder in children and adolescents. CNS drugs, 15 (2), 93-104.

Morrissey, M. (2013). EMDR as an integrative therapeutic approach for the treatment of separation anxiety disorder. Journal of EMDR Practice and Research, 7 (4), 200-207.

Muris, P. ve Meesters, C. (2002). Attachment, behavioral inhibition, and anxiety disorders symptoms in normal adolescents. Journal of Psychopathology and Behavioral Assessment, 24 (2), 97-106.

Muris, P., Meesters, C., Melick, M. V. ve Zwambag, L. (2001). Self-reported attachment style, attachment quality, and symptoms of anxiety and depression in young adolescents. Personality and Individual Differences, 30 (1), 809-818.

Phelps, L., Cox, D. ve Bajorek, E. (1992). School phobia and separation anxiety: Diagnostic and treatment comparisons. Psychology in the Schools, 29 (4), 384-394. 
Sümer, N., Sayıl, M. ve Berument, S. K. (2016). Anne duyarlılı̆ı ve çocuklarda bağlanma (1. Baskı). İstanbul: Koç Üniversitesi Yayınları.

Türkbay, T. ve Söhmen, T. (2001). Ayrılma kaygısı bozukluğunda bireysel ve ailesel etmenler. Çocuk ve Gençlik Ruh Sağlığı Dergisi, 8 (1), 77-84.

Warren, S. L., Huston, L., Egeland, B. ve Sroufe, L. A. (1997). Child and adolescent anxiety disorders and early attachment. American Academy of Child and Adolescent Psychiatry, 36 (5), 637-644.

Wright, J. C., Binney, V. ve Smith, P. K. (1995). Security of attachment in 8-12-year-olds: A revised version of the separation anxiety test, its psychometric properties and clinical interpretation. Child Psychology and Psychiatry, 36 (5), 757-774. 